University of Nebraska - Lincoln

DigitalCommons@University of Nebraska - Lincoln

Faculty Publications from Nebraska Center for Research on Children, Youth, Families, and Schools
Children, Youth, Families \& Schools, Nebraska Center for Research on

2012

\title{
Two Approaches to Teaching Young Children Science Concepts, Vocabulary, and Scientific Problem-Solving Skills
}

\author{
Soo-Young Hong \\ University of Nebraska - Lincoln, shong5@unl.edu \\ Karen E. Diamond \\ Purdue University
}

Follow this and additional works at: https://digitalcommons.unl.edu/cyfsfacpub

Part of the Pre-Elementary, Early Childhood, Kindergarten Teacher Education Commons

\begin{abstract}
Hong, Soo-Young and Diamond, Karen E., "Two Approaches to Teaching Young Children Science Concepts, Vocabulary, and Scientific Problem-Solving Skills" (2012). Faculty Publications from Nebraska Center for Research on Children, Youth, Families, and Schools. 27.

https://digitalcommons.unl.edu/cyfsfacpub/27
\end{abstract}

This Article is brought to you for free and open access by the Children, Youth, Families \& Schools, Nebraska Center for Research on at DigitalCommons@University of Nebraska - Lincoln. It has been accepted for inclusion in Faculty Publications from Nebraska Center for Research on Children, Youth, Families, and Schools by an authorized administrator of DigitalCommons@University of Nebraska - Lincoln. 


\title{
Two Approaches to Teaching Young Children Science Concepts, Vocabulary, and Scientific Problem-Solving Skills
}

\author{
Soo-Young Hong ${ }^{\mathrm{a},{ }^{*}}$, Karen E. Diamond ${ }^{\mathrm{b}}$ \\ aDepartment of Child, Youth and Family Studies, College of Education and Human Sciences, University of Nebraska-Lincoln, \\ Lincoln, Nebraska, USA \\ ${ }^{\text {b}}$ Department of Child Development and Family Studies, Purdue University, West Lafayette, Indiana, USA
}

Article received October 13, 2010; received in revised form September 5, 2011; accepted September 27, 2011

*Corresponding author. E-mail addresses: shong5@unl.edu, kdiamond@purdue.edu.

Keywords: Preschool science, Teaching approaches, Science concepts and vocabulary, Scientific problem-solving skills

\begin{abstract}
The present study examined the efficacy of two different approaches to teaching designed to facilitate children's learning about science concepts and vocabulary related to objects' floating and sinking and scientific problem-solving skills: responsive teaching (RT) and the combination of responsive teaching and explicit instruction (RT + EI). Participants included 104 children (51 boys) aged four to five years.Small groups of children were randomly assigned to one of the two intervention groups (RT, RT + EI) or to a control group. Responsive teaching (RT) reflects a common approach to teaching young children, and the combination approach (RT + EI) includes explicit instruction as well as responsive teaching. The two planned interventions were implemented with preschool children and provided evidence that (1) young children learned science concepts and vocabulary better when either responsive teaching or the combination of responsive teaching and explict instruction was used; (2) children in the combined intervention group learned more science concepts and vocabulary and more content-specific scientific problem-solving skills than children in either the responsive teaching or control groups. Limitations, future directions, and implications for practice are also discussed.
\end{abstract}

Developmentally appropriate practice (DAP) provides an important set of guidelines and principles for teaching children in early childhood classrooms. In its latest formulation (Copple \& Bredekamp, 2009), DAP emphasizes that teachers should provide a balance of child-initiated and teacher-guided opportunities for young children to explore and learn about the world around them. However, we know little about effective strategies for teaching and learning in early childhood (National Research Council, 2001). In addition, many preschool teachers have interpreted developmentally appropriate practice to mean that children should construct knowledge on their own without explicit instruction (National Research Council, 2001).

\section{Effective instruction for preschool classrooms}

In this study, we examine two common but different instructional approaches to teaching young children science concepts and vocabulary and scientific problemsolving skills. Responsive teaching (RT) represents a childinitiated and child-directed constructivist perspective in which teachers provide materials and opportunities for exploration and experimentation, but without explicitly and systematically teaching specific concepts. Guided by the work of Piaget, constructivist preschool teachers provide support and facilitate children's learning by encouraging children's self-direction and arranging potential cognitive conflicts without explicitly providing information (Chaille \& Britain, 1991; Forman \& Kuschner, 1983). In other words, teachers are considered to use this approach when they follow a child's lead and facilitate children's exploration by using strategies such as modeling, imitating, playing in parallel with children, describing what children are doing and saying, and providing materials in an environment that challenges children's thinking.

Adifferent, butcomplementary, approachfor teachingyoung children important content includes guiding and supporting children's learning using explicit as well as implicit strategies that best fit each child's level of understanding and skills. According to this perspective, the early childhood teacher sometimes needs to use teaching strategies that extend the ones used in teaching from a constructivist perspective (Berk \& Winsler, 1995; Copple \& Bredekamp, 2009; Rogoff, 1990; Vygotsky, 1978). Specific strategies include explicitly introducing concepts and vocabulary words to which children may not be familiar, directly asking open-ended and challenging questions, and conducting experiments, along with responsive teaching approaches.

The primary goal of the present study is to examine the efficacy of two different types of instructional strategies for teaching preschool children science concepts, vocabulary, and scientific problem-solving skills. The strategies contrast a constructivist approach (Responsive Teaching: RT) with one that includes more explicit instruction (Responsive Teaching + Explicit Instruction: RT + EI). These two different instructional approaches were used, in this study, to teach preschool children concepts related to objects' floating and sinking. We chose this concept because water play with objects that float and sink is a common activity in many early childhood classrooms (Dodge, Colker, \& Heroman, 2002). A full understanding of floating and sinking requires an appreciation of co-relations between weight and size (density), and mass (which involves the concept of gravity). While preschool children are unlikely to learn fully these sophisticated associations, developmentally appropriate 
learning goals for floating and sinking activities include (a) understanding how to measure and compare the weights of different objects using a balance scale, and (b) understanding that a heavier object is more likely to sink in water when two objects' size is held constant. In the same way, children may understand that a larger object is more likely to float in water when two objects' weights are the same. Rather than learning complex concepts of density and mass, preschool children may begin learning narrower associations between weight and size and buoyancy.

The debate about the teachers' role appears often in discussions of science teaching in early childhood classrooms. Should teachers include explicit instruction in teaching young children science concepts and scientific problem-solving skills while responsively reacting to children's interest and exploration? Butts, Hoffman, and Anderson (1993) addressed the question, "Is hands-on experience enough?" in their study of children's understanding of sinking and floating. Participants were five- to six-year-old children, primarily from middle- and low-SES minority families, who watched a video about floating and sinking and then engaged in hands-on experience with objects. They found no significant improvement in the proportion of correct judgments about whether objects would float or sink after this intervention. However, after experiencing instructional conversations focused on floating and sinking in groups (e.g. making predictions and experiments related to objects' floating and sinking, recording their discoveries, constructing floating and sinking rules with adults), researchers found that significantly more children performed the task successfully.

Tenenbaum, Rappolt-Schlichtmann, and Zanger (2004) showed that classroom lessons and an expert's modeling combined with hands-on activity were effective in teaching children science concepts related to objects' buoyancy, bubbles, and currents. They investigated the effectiveness of science teaching that involved a combination of classroom lessons with museum visits. This was an experimental study that included three intervention classrooms (30 children) and three control classrooms (18 children). Children in the intervention group received classroom lessons on water (i.e. buoyancy, bubbles, and currents) and visited science exhibits on the same topics. Children in the control group did not receive classroom lessons about water and visited other museum exhibits, such as social and literacy exhibits. Children in both groups were asked the same questions regarding buoyancy, bubbles, and currents as pre- and posttests. Results revealed that children in the intervention group gave significantly more complex explanations for objects' buoyancy, listed more correct ingredients in bubbles, and gave more correct definitions of currents at posttest. However, because classroom lessons and science exhibits were not separated in the research design, it is not possible to determine which of the intervention components (lessons, exhibits) led to children's learning.

\section{Why science as a context of learning?}

The goal of early childhood science education should be "to develop each child's innate curiosity about the world; to broaden each child's procedural and thinking skills for investigating the world, solving problems, and making decisions; and to increase each child's knowledge of the natural world" (Bredekamp \& Rosegrant, 1995, p. 45). Helping children increase their knowledge of the natural world is related to teaching science concepts and knowledge. Helping children learn procedural and thinking skills for investigation is related to promoting children's science inquiry, including both content-general and content-specific problem-solving skills (French, 2004). The basics of the goals for science education remain the same for kindergarten through early elementary grades, but the levels and complexity of knowledge provided are different (National Research Council, 1996). Scientific problem-solving strategies include making predictions and observations, analyzing information, and forming conclusions. Scientific thinking or problemsolving skills are important components of most states' early learning standards (Scott-Little, Kagan, \& Frelow, 2006) and "contextually rich inquiry experiences" provide a realistic basis for science activities in early education classrooms (Mantzicopoulos, Samarapungavan, \& Patrick, 2009, p. 314).

Science activities in early childhood classrooms generally engage children's interest and encourage them to actively participate (French, Conezio, \& Boynton, 2000; Greenfield et al., 2009). Often science activities enable children to act on various materials and to become curious about the results of their action (e.g. what will happen if I mix red and white paint? What will happen if I put the Lego piece in water?). However, there are few data on effective strategies to teach preschool-age children science concepts and scientific problem-solving skills. Specific aims of the current study were to examine the effect of specific types of instructional approaches to teaching (RT vs. RT + EI) on children's learning about science concepts and vocabulary and their scientific problem-solving skills.

\section{Current study}

The present study is designed to examine the efficacy of two different instructional strategies for teaching preschool children science concepts, vocabulary, and scientific problemsolving skills. We hypothesize that teaching approaches will be related to children's learning: children whose teacher provides both explicit and implicit (responsive) instruction $(\mathrm{RT}+\mathrm{EI})$ will outperform children receiving only responsive instruction (RT) on all three outcomes (i.e. concepts and vocabulary, content-general, and content-specific scientific problem-solving skills); and children in the RT group will outperform those in the control group. Multilevel modeling was used to analyze the nested data.

\section{Method}

4.1. Participants

Participants included 104 children (51 boys) aged four to five years (mean age $=57.6$ months; $S D=5.6$ ) attending early childhood programs in a mid-size midwestern community and their parents. Fifty-one children attended half-day ( $n$ $=10$ classrooms), and 53 attended full-day early childhood programs ( $n=8$ classrooms). The demographic information of the sample is provided in Table 1 (i.e. child's ethnicity, child's age, child's gender, and mother's education).

\subsection{Study design and procedure}

Directors of nine early childhood programs were contacted and given consent forms, letters, and recruitment flyers 
Table 1

Background information and group difference

\begin{tabular}{|c|c|c|c|c|}
\hline & $\mathrm{RT}(n=35)$ & $\mathrm{RT}+\mathrm{EI}(n=37)$ & Control $(n=32)$ & Total $(N=104)$ \\
\hline \multicolumn{5}{|l|}{ Child's Age in Months } \\
\hline$<60$ months & 20 & 24 & 20 & 64 \\
\hline$\geq 60$ months & 15 & 13 & 12 & 40 \\
\hline \multicolumn{5}{|l|}{ Child's Gender } \\
\hline Girls & 17 & 20 & 16 & 53 \\
\hline Boys & 18 & 17 & 16 & 51 \\
\hline \multicolumn{5}{|l|}{ Child's Ethnicity } \\
\hline Non-White & 10 & 11 & 12 & 33 \\
\hline White & 25 & 26 & 20 & 71 \\
\hline \multicolumn{5}{|l|}{ Mother's Education } \\
\hline No college degree & 9 & 4 & 13 & 16 \\
\hline College degree & 13 & 17 & 8 & 38 \\
\hline Advanced degrees & 13 & 16 & 11 & 40 \\
\hline
\end{tabular}

Note. No significant group differences were found; RT: Responsive Teaching; RT + EI: Responsive Teaching with Explicit Instruction.

explaining this study, and they provided the information to parents of four- and five-year-old children from 18 classrooms. Approximately 337 sets of recruitment forms were sent to directors, and 108 sets $(32 \%)$ were returned with parents' consent. It is not possible to determine how many forms were distributed to parents.

After pretest, children were randomly assigned to small group instruction with one to three classmates (35 groups), and the small groups were then randomly assigned to an instructional condition: Responsive Teaching (RT; $n=35$ children), Responsive Teaching and Explicit Instruction (RT + EI; $n=37)$, and Control $(n=32)$. When there was more than one small group from a single classroom, those groups were assigned to different instructional conditions. The pretest results did not affect how children were assigned to groups. Each child was pulled out from his or her classroom to participate in the intervention group in order to reduce contamination from classroom materials, peers, and adults.

Four 15-min intervention sessions focused on objects' floating and sinking were implemented by the first author with the two intervention groups, and four book-reading sessions were provided also by the first author for the control group. The full cycle of each intervention took approximately two to two and a half weeks. Each session was videotaped. Assessments of science concepts and vocabulary and scientific problem-solving skills related to sinking and floating were completed about one week before and after the four intervention sessions. Children had met with the implementer once before the interventions because the implementer administered the pretest before children were randomly assigned to small groups. Research assistants who were blind to the intervention conditions and who had not participated in the interventions administered the posttest.

The goals of science learning and the focus of the science lessons were the same for both interventions. The overall learning goals for this intervention were to help children: (1) understand the concepts of size and weight and their relation to floating and sinking by measuring and comparing objects with different properties; (2) make correct judgments about whether an object would float or sink by using scientific problem-solving strategies, such as prediction, measurement, observation, comparison, and categorization; and (3) learn to make an object that floats sink and to make an object that sinks float by using scientific problem-solving strategies. In the RT intervention, the lessons were taught by choosing and providingmaterials thatwould promoteanunderstanding of sinking and floating. The implementer in this intervention condition described children's behavior, commented on and asked questions about what children did and said, but did not provide explicit instruction (e.g. providing a lesson about how to measure weight) or direct the play activity. In contrast, Responsive Teaching and Explicit Instruction $(\mathrm{RT}+\mathrm{EI})$ used both implicit (RT) and explicit strategies to teach science vocabulary, concepts, and problem-solving skills. In addition to providing implicit teaching as used in the RT intervention (e.g. describing children's behavior and commenting on what they did), the implementer explicitly taught science concepts and vocabulary and scientific problem-solving methods by providing a brief lesson (i.e. $10 \mathrm{~min}$ ) at the beginning of each session (see Table 2 for an example of the distinction). Specific concepts that were taught included scientific problem-solving skills (i.e. sorting, categorizing, and making experiments) and specific concepts and vocabulary that were related to objects' floating and sinking (e.g. size, weight, float, sink, large, small, heavy, and light). In terms of making experiments, children were expected to learn to make hypotheses, test hypotheses, and modify their hypotheses when the original ones were not supported. For example, children were first asked to verbally provide ideas on how they could make a plastic container that floats sink (i.e. making hypotheses; push it down). Then they had a chance to act out what they had hypothesized (i.e. testing hypotheses; actually push down the container). If one of the hypotheses did not work, children were asked to provide other ideas (i.e. modifying hypotheses; put rocks in the container).

The goal for the book-reading sessions for the control group was also to teach children science concepts and vocabulary, but the topics that were taught using the books were related to biological science, not physical science (e.g. five senses, worms, seeds, etc.) because there were few books on physical science for preschoolers at the time this study was implemented and also because life science tends to be what preschoolers experience the most in their own classroom (Greenfield et al., 2009). While reading these books in small groups, the implementer pointed to the pictures, 
Table 2

Examples: Distinction between RT and RT + EI.

General Description

Teaching how to measure and compare weight using a balance scale
Responsive Teaching

The implementer did not enter but observed children's play for the first 5-10 min while making notes about what children did and said. Then the implementer participated in the play.

The implementer did not initiate the activity. After observing children's play for 5-10 min, she played with children in parallel, and modeled how to use the balance scale to measure or compare weight of objects by putting one object in one bucket and blocks in the other or putting one object in one bucket and another object in the other bucket. The implementer sometimes said, "Hmm this bottle is heavier than this (the other) one. This side went down," but not all the children heard what the implementer said. Some children who heard what the implementer said showed interest in the balance scale and tried to manipulate it.
Teaching the heavier object sinks The implementer tried to implicitly teach the relation in water when two objects are between object's weight and its floating and sinking by the same size and only one sinks describing what children were doing. "C is putting one bottle in the water. It went down to the bottom. It sank." While playing with children, the implementer measured weight of various objects using the balance scale whether or not children were observing what she was doing. In addition, implementer put two objects that look similar in water and observed what happened.

Teaching how to make an object floats sink
The implementer described what children were doing with plastic container, small bottles, etc. and described what they were doing. " $\mathrm{A}$ is putting small rocks in the container." "T is helping A put bigger rocks in there, too! That now looks so heavy." When the child accidentally or intentionally dropped the container in the water, the implementer said, "It sank in the water. With all those rocks, it must have become very heavy." Again, not all the children were paying attention to what the implementer said or did.
Responsive Teaching + Explicit Instruction

The implementer provided an explicit instructional lesson at the beginning of each session for about 5-10 $\mathrm{min}$. Then children explored the materials, and the implementer participated in the play.

The implementer started a lesson about objects' weight by saying, "We are going to learn about 'weight' today." She asked questions, such as "Do you know what weight means? What does weight mean?" The implementer acknowledged children's responses by saying, "That is right! Weight tells us how heavy things are and how light things are. How do you know that something is heavier than the other? Which one do you think is heavier?" After collecting children's thoughts, the implementer asked again, "We can measure the weight of objects using this tool. Do you know what this is called?" "This is called a balance scale. I will show you how to use this balance scale to measure weight. I will put this pipe in one bucket, and have K (one of the children) put blocks in the other bucket. Put them one by one so that we can count how many blocks we need." After the weight of each object was measured, the implementer wrote down the number of blocks needed on a large piece of paper attached to the wall near the group and compared the weight of the objects with children.

The implementer tried to explicitly teach the relation between an object's weight and its floating and sinking in a limited circumstance (between two objects one of which was expected to float and the other to sink). "As you can see, these two pipes look the same, but this one is heavier than the other one. You can hold them to feel the weight. Which one is heavier? Now, we will make some

predictions. If we put these two pipes in the water, which one do you think will sink in the water?" After gathering children's predictions by writing them down on a chart, the implementer asked each child to put one thing in the water and observe what happened.

The implementer first reviewed what children learned in the previous sessions by asking the question, "Do you remember what we learned last time?" After reviewing previous sessions briefly, the implementer introduced several different objects (e.g. plastic containers, small water bottles, boats, different sized rocks, etc.), and asked, "Do you think this bottle will float or sink in the water?" Then she had children put them in water and see what happened. Then she asked, "How can we make this bottle Sink in the water? Who can tell me how we can make it sink? I need some good ideas to make this sink in the water." When children provided their ideas, the implementer wrote them down on a large piece of paper. "These are our predictions, and now let's see if these actually work." Then the implementer had children take turns carrying out the predictions and see whether the objects sank in the water. While doing this, she asked, "what can we do to..." and "why" questions. After the lesson, children were encouraged to explore materials and make things that float sink in the water. asked questions about the pictures and children's previous experience, answered children's questions, and discussed what they learned from the books. These book-reading sessions did not include a time for a specific lesson (cf. RT + EI had a 10-min lesson per session) and were not about objects' floating and sinking, but the implementer explained new vocabulary words to children using the pictures in the books and answered questions asked by children. No props were used in book-reading sessions.

\subsection{Measures}

\subsubsection{Science concepts and vocabulary}

Concepts and vocabulary were assessed prior to and following the intervention. Vocabulary words included: size, weight, float, sink, large/big, small, heavy, light, larger/bigger, smaller, heavier, lighter, like, and different. These words were chosen because they were closely related to the content of the interventions and because one of the goals of the intervention was to give children an opportunity to learn new words as well as the meanings and ideas represented by the words and objects (i.e. concepts). Children were either asked to explain the meaning of the words (e.g. what is size?), point to the correct picture (e.g. point to the picture of 'large'), or choose an object that represents the presented concept (e.g. which one is heavier?). In addition, as an assessment of science concepts, children were asked to make judgments about whether or not an object would float or sink when put in water. The objects presented to children during pre- and posttests were different objects from those used in intervention sessions. Each item 
was scored as ' 1 ' if the response was correct or ' 0 ' if incorrect. The total vocabulary and concepts score was calculated by summing all item scores ( 22 items; possible range $=0-42$ ). The internal consistencies of the items measured by Cronbach's alpha were $a=0.77$ (pretest) and $\alpha=0.86$ (posttest). The significant and strong correlation between this measure and the Woodcock-Johnson III Picture Vocabulary subtest $(r=0.64$; $p<0.001)$ adds validity to this measure created by the authors.

\subsubsection{Scientific problem-solving skills}

The skills assessed were sorting and categorizing (Part I: content-general skills) and making experiments (Part II: content-specific skills). For Part I, children were asked to sort four objects by weight and then by size (the number of objects that were correctly sorted became the score; possible range in score $=0-8$ ) and categorize six objects by their weight and size ( 0 for incorrect and 1 for correct responses; possible range in score $=0-2$ ). These process skills were not explicitly taught during intervention sessions but were included in assessments to examine whether these general science process skills were also learned through the interventions. For Part II, children were asked to construct and test hypotheses regarding the ways they could make an object that floats sink and make an object that sinks float (As noted earlier, the objects used to assess these skills were different from those used in intervention sessions). The internal consistencies of the items measured by Cronbach's alpha were $\alpha=0.66$ (pretest) and $\alpha=0.58$ (posttest) for Part I and $\alpha=0.83$ (pretest) and $\alpha=0.88$ (posttest) for Part II.

\subsubsection{Data reduction}

For all three outcomes, children's responses to open-ended questions were coded as ' 0 ' if the response was incorrect; and the other responses were coded inductively taking into account the sophistication of the child's response. More specifically, for science concepts and vocabulary outcome, children's responses to open-ended questions were coded as ' 1 ' if the response was acceptable; and ' 2 ' if the response was correct. For content-specific problem-solving outcome, first, a score was given to those who tried but failed or succeeded in experimentation (i.e. $0=$ I don't know or No trial; $1=$ one trial but failed and gave up; 2 = two or more trials but failed and gave up; 3 = succeeded after one or more trials; 2 items; possible range $=0-6)$. Then, children's responses, recorded verbatim, were coded by researchers depending on the accuracy of the responses (i.e. $0=\mathrm{I}$ don't know or incorrect; $4=$ accurate and correct; 2 items; possible range $=0-8$ ). These responses were also coded inductively taking into account the sophistication of the child's response. The specific ways to code these qualitative items are described in Appendix A, and average inter-coder percent agreements ranged from $89 \%$ to $98 \%$.

\subsubsection{Expressive vocabulary skills}

Children's expressive vocabulary skills were measured by the Woodcock-Johnson III Picture Vocabulary Test. Each child was asked to name the pictured objects, and the items became increasingly difficult toward the end of the test. Reliability reported by test developers is 0.77 in the ages five to 19 (Mather \& Woodcock, 2001). The $W$ score, a standardized score with equal intervals, was used in the analysis. $W$ scores are centered at 500, the average score of a 10 -year-old child. Unlike standard scores, $W$ scores provide a way to assess individual growth using standardized scores.

\subsubsection{Attendance}

The percentage of children's attendance in both the intervention and the control sessions was calculated. About $70 \%$ of the children attended all sessions, and $20 \%$ attended three out of four sessions ( $M=86.3 \%$; $S D=22.54)$. There was no significant difference in attendance between groups, and none of the outcome variables were significantly associated with children's attendance.

\subsubsection{Fidelity of interventions}

Fidelity of intervention checklists were developed reflecting critical components for each intervention (18 items for RT; 17 items for RT + EI). Eight items under RT were those related to explicit instruction, which must have not happened during the RT sessions (e.g. Did the implementer tell children what the objective of the activity is? Did the implementer direct the activity? Did the implementer directly teach vocabulary? Did the implementer directly pose a problem?). These checklists were completed by a research assistant who was not the implementer using the videos of each session of each intervention. The fidelity of intervention was measured for each intervention session for both RT and RT + EI interventions and each session for the control group. Each item was scored as a 1 (observed) or a 0 (not observed). A score representing the proportion of items completed in each session was calculated (possible ranges $=0-100$ for both intervention groups).

Higher scores indicated that a larger percentage of critical elements of the intervention occurred in each session (with $100 \%$ indicating that all critical elements were included in the session). Those eight items under RT that must not occur during intervention sessions were coded in reverse before the overall fidelity score was calculated for RT sessions. If all the critical components (10 items) have occurred and if none of the components that must not have occurred (8 items) occurred, that session was considered to meet $100 \%$ of the fidelity of the implementation.

We coded control group session using RT + EI fidelity checklist, in order to determine the extent to which instruction planned for the intervention groups was also included in control group session. For the control sessions, all fidelity measure items were coded in reverse; a higher score indicated that planned elements of the intervention did not occur in control group sessions.

Reliability checks were conducted on 24 intervention and eight control sessions (25\% of the data). Average inter-coder percent agreement was 92\% (range: 88-97\%; Cohen's Kappa $=0.86$ ) for intervention and $99 \%$ (range: $97-100 \%$ ) for control sessions. Average fidelity was $93.1 \%$ across all intervention sessions $(\mathrm{SD}=3.05$, range $=88.24-100)$ and $97 \%$ for control sessions $(\mathrm{SD}=4.44$, range $=88.24-100)$.

\subsubsection{Demographic information}

Parents were asked to complete a questionnaire that included demographic information, such as child's birth date, child's gender and ethnicity, and mother's educational level.

\subsubsection{Academic interaction at home}

A measure of parent-child academic interaction at home was adapted from a scale used in Roopnarine, Krishnakumar, Metindogan, and Evans (2006). A parent of each child reported how often during a given week $(1=$ not at all, $2=$ 
Table 3

\begin{tabular}{|c|c|c|c|c|c|c|}
\hline \multicolumn{7}{|l|}{ Descriptive statistics and group difference } \\
\hline Variables & $N$ & Min & \multicolumn{2}{|c|}{ Mean (SD) } & $\operatorname{Max}$ & \multirow[t]{2}{*}{ Group Difference } \\
\hline$\%$ Attendance (1-100) & 104 & 25.00 & 87.44 & $(22.54)$ & 100.00 & \\
\hline RT & 35 & 25.00 & 94.28 & $(12.26)$ & 100.00 & \multirow{3}{*}{$n s}$. \\
\hline $\mathrm{RT}+\mathrm{EI}$ & 37 & 50.00 & 85.14 & $(23.17)$ & 100.00 & \\
\hline Control & 32 & 25.00 & 82.91 & $(27.76)$ & 100.00 & \\
\hline Child's Age in Months Time 1 & 104 & 47.00 & 57.62 & $(5.6)$ & 68.00 & \multirow{6}{*}{$n s$. } \\
\hline RT & 35 & 49.00 & 58.06 & $(5.29)$ & 68.00 & \\
\hline $\mathrm{RT}+\mathrm{EI}$ & 37 & 48.00 & 56.95 & $(5.38)$ & 68.00 & \\
\hline Control & 32 & 47.00 & 57.91 & $(6.23)$ & 68.00 & \\
\hline Parent-Child Academic Interaction at Home & 10 & 41.00 & 2.99 & $(0.84)$ & 5.00 & \\
\hline RT & 35 & 1.00 & 3.05 & $(0.96)$ & 5.00 & \\
\hline $\mathrm{RT}+\mathrm{EI}$ & 37 & 1.00 & 2.97 & $(0.73)$ & 4.25 & \multirow[t]{2}{*}{$n s}$. \\
\hline Control & 32 & 1.25 & 2.94 & $(0.84)$ & 5.00 & \\
\hline Concepts and vocabulary Time $1(0-42)$ & 10 & 49.00 & 21.97 & $(6.78)$ & 36.00 & \multirow{5}{*}{$n s$. } \\
\hline RT & 35 & 9.00 & 22.43 & $(7.86)$ & 36.00 & \\
\hline $\mathrm{RT}+\mathrm{EI}$ & 37 & 12.00 & 22.49 & $(5.49)$ & 35.00 & \\
\hline Control & 32 & 9.00 & 20.88 & $(6.95)$ & 34.00 & \\
\hline Concepts and vocabulary Time $2(0-42)$ & 104 & 9.00 & 27.86 & $(8.0)$ & 42.00 & \\
\hline $\mathrm{RT}+\mathrm{EI}$ & 37 & 15.00 & 33.46 & $(5.58)$ & 42.00 & \multirow{4}{*}{$\begin{array}{l}F(2,101)=23.09, p<0.001 \\
(\mathrm{RT}+\mathrm{EI}>\mathrm{RT}>\text { Control) } \\
\text { (Sorting and Categorizing) }\end{array}$} \\
\hline Control & 32 & 9.00 & 22.69 & $(6.69)$ & 35.00 & \\
\hline Problem-Solving I Time 1 (0-10) & 104 & 0.00 & 6.47 & $(2.93)$ & 10.00 & \\
\hline RT & 35 & 1.00 & 6.66 & $(2.72)$ & 10.00 & \\
\hline $\mathrm{RT}+\mathrm{EI}$ & 37 & 0.00 & 7.00 & $(2.79)$ & 10.00 & \multirow[t]{2}{*}{ ns. } \\
\hline Control & 32 & 0.00 & 5.66 & $(3.20)$ & 10.00 & \\
\hline Problem-Solving I Time 2 (0-10) & 104 & 2.00 & 8.01 & $(2.35)$ & 10.00 & \multirow{6}{*}{$\begin{array}{l}F(2,101)=3.86, p<0.05 \\
(\mathrm{RT}+\mathrm{EI}>\mathrm{RT}>\text { Control) } \\
\text { (Making Experiments) }\end{array}$} \\
\hline RT & 35 & 4.00 & 8.26 & $(1.87)$ & 10.00 & \\
\hline $\mathrm{RT}+\mathrm{EI}$ & 37 & 2.00 & 8.57 & $(2.26)$ & 10.00 & \\
\hline Control & 32 & 2.00 & 7.09 & $(2.72)$ & 10.00 & \\
\hline Problem-Solving II Time 1 (0-22) & 104 & 1.00 & 12.89 & $(4.92)$ & 22.00 & \\
\hline RT & 35 & 7.00 & 14.20 & $(4.61)$ & 22.00 & \\
\hline $\mathrm{RT}+\mathrm{EI}$ & 37 & 3.00 & 13.49 & $(5.19)$ & 22.00 & \multirow[t]{2}{*}{ ns. } \\
\hline Control & 32 & 1.00 & 10.78 & $(4.34)$ & 22.00 & \\
\hline Problem-Solving II Time 2 (0-22) & 104 & 2.00 & 15.89 & $(5.33)$ & 22.00 & \multirow{4}{*}{$\begin{array}{l}F(2,101)=13.49, p<0.001 \\
(\mathrm{RT}+\mathrm{EI}>\mathrm{Control})\end{array}$} \\
\hline RT & $34^{*}$ & 2.00 & 16.54 & $(5.35)$ & 22.00 & \\
\hline $\mathrm{RT}+\mathrm{EI}$ & 37 & 6.00 & 18.30 & $(3.99)$ & 22.00 & \\
\hline Control & 32 & 2.00 & 12.41 & $(4.97)$ & 22.00 & \\
\hline $\mathrm{RT}+\mathrm{EI}$ & 37 & 452.00 & 473.16 & $(11.03)$ & 501.00 & \multirow[t]{2}{*}{$n s$. } \\
\hline Control & 32 & 452.00 & 470.50 & $(10.91)$ & 494.00 & \\
\hline Mean Fidelity (0-100) & 104 & 88.24 & 94.41 & $(3.51)$ & 100.00 & \multirow{4}{*}{$n s$. } \\
\hline RT & 35 & 88.89 & 93.53 & (2.98) & 98.61 & \\
\hline $\mathrm{RT}+\mathrm{EI}$ & 37 & 88.24 & 92.69 & (3.11) & 100.00 & \\
\hline Control & 32 & 88.24 & 97.00 & $(4.44)$ & 100.00 & \\
\hline
\end{tabular}

Note. ${ }^{*}$ One outlier was eliminated (the child was very quiet and did not want to say anything while being tested; score = 384); RT: Responsive Teaching; RT + EI: Responsive Teaching with Explicit Instruction.

Table 4

Correlations among children's age and science outcomes

Age in Months Age in Months C-V Time 1

C-V Time 1

$0.30^{*}$

P-S I Time $2 \quad 0.43^{*}$

P-S II Time $1 \quad 0.22^{*}$

P-S II Time $2 \quad 0.14$

P-V Time 1

$0.32^{*} \quad 0.64^{*}$

$\begin{array}{ll}0.66^{*} & \\ 0.52^{*} & 0.43^{*} \\ 0.47^{*} & 0.53^{*} \\ 0.49^{*} & 0.42^{*} \\ 0.40^{*} & 0.54^{*} \\ 0.64^{*} & 0.47^{*}\end{array}$

$0.74^{*}$
$0.20^{*}$
0.18
$0.48^{*}$

$0.21^{*}$

$0.190 .58^{*}$

$0.47^{*} \quad 0.39^{*}$

Note. *p < 0.05; C-V: concept-vocabulary; P-S I: sorting and categorizing; P-S II: making experiments; and P-V: Picture Vocabulary W scores.

rarely, 3 = sometimes, 4 = almost always, $5=$ always) he or she engaged in (1) teaching the child about things she/he did not understand in school, (2) doing homework (includes work sent home from school and work that parents give children at home), (3) engaging in science activities (e.g. growing seeds, experimenting with objects' floating and sinking, working with magnets, etc.), and (4) doing math with the child (e.g. addition and subtraction, counting, etc.). The internal consistency of these items was $\alpha=0.67$ (mean $=2.99$; $\mathrm{SD}=$ 0.84 ). We included this scale in the study to see whether the intervention groups and the control group were equivalent in terms of interactions at home after randomization.

\section{Results}

Descriptive statistics were calculated for each variable, including measures of fidelity of implementation (see Table $3)$. Correlations between science concepts and vocabulary and scientific problem-solving skills at pretest and posttest are presented in Table 4. Both outcomes were significantly associated with children's initial expressive vocabulary skills $(r=0.25-0.64)$. There were no significant differences between 


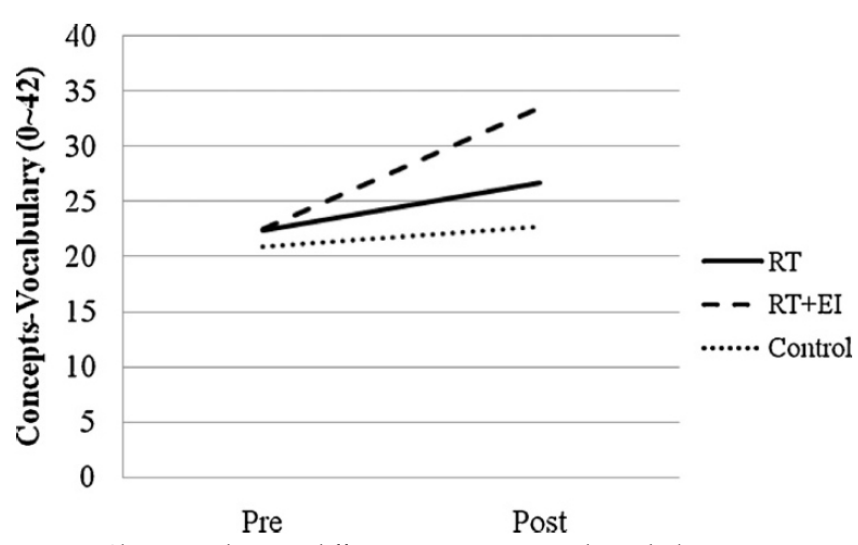

Figure 1. Change and group difference in concepts and vocabulary outcome

the two intervention groups and the control group on any background variables or parent-child academic interactions at home (see Table 1). There were no significant group differences in children's initial performance for science concepts and vocabulary outcome and both content-general (Part I: sorting and categorizing) and content-specific (Part II: making experiments) scientific problem-solving outcomes. There was no significant difference in attendance between groups, and none of the outcome variables were significantly associated with children's attendance. Therefore, attendance wasnotincludedintheanalysis. Wehypothesized that teaching approaches would be related to children's learning. Analyses used two-level multi-level modeling due to significant between-group variability in outcomes (level one-children; level two-small groups). The equations are as follows:

Level One (Children):

VCTime2 $=\beta_{0 j}+\beta_{1 j}$ VCTime1 $_{i j}+r_{i j}$ PS1Time2 $=\beta_{0 j}+\beta_{1 j}$ PS1Time $_{i j}+r_{i j}$ PS2Time2 $=\beta_{0 j}+\beta_{1 j}$ PS2Time1 $_{i j}+r_{i j}$

Level Two (Small groups):

$\beta_{0 \mathrm{j}}=\gamma_{00}+\gamma_{01}$ Condition1 $(\mathrm{RT})_{\mathrm{j}}+\gamma_{02}$ Condition2(RTEI) $)_{j}+U_{0 j}$ $\beta_{1 \mathrm{j}}=\gamma_{10}+\gamma_{11}$ Condition1(RT) $)_{j}+\gamma_{12}$ Condition2(RTEI) $)_{j}+U_{1 j}$ $\gamma_{i j}: N\left(0, \sigma^{2}\right)$

$\left(\begin{array}{l}U_{0 j} \\ U_{1 j}\end{array}\right): N\left[\left(\begin{array}{l}0 \\ 0\end{array}\right)\left(\begin{array}{l}\tau_{00} \tau_{01} \\ \tau_{10} \tau_{11}\end{array}\right)\right]$

First, we created level-1 (child level) models for each outcome variable (i.e. VCTime2 $=$ Concepts and vocabulary at posttest, PS 1 Time 2 = Problem-solving Part I at posttest, and PS 2 Time 2 = Problem-solving Part II at posttest). The only control variable at the child's level was her initial performance (i.e. VCTime 1, PS 1 Time 1, and PS 2 Time 2) because none of the other relevant variables (i.e. child's age, gender, ethnicity, and academic interaction at home) was significantly related to outcome variables. We did not include child's expressive vocabulary scores into the model because they were strongly correlated with the child's initial performance on the outcome measures. Then, we modeled at the small-group level with two dummy variables for condition (i.e. Condition 1 = RT, Condition 2 = RT + EI, when both were

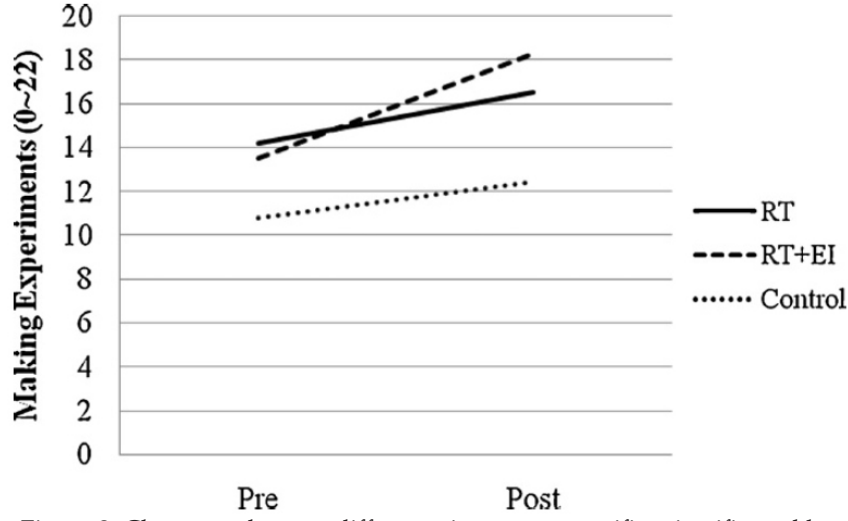

Figure 2. Change and group difference in content-specific scientific problemsolving skills outcome (making experiments). Note. No significant group difference was found at pretest

zero, that meant it was control group). Condition was the only level-2 predictor in the current study. All the analyses were conducted using the SAS PROC MIXED procedure.

Results revealed significant effects of instructional approach. For the science concepts and vocabulary outcome, children in the RT and RT + EI groups outperformed those in the control group after controlling for children's initial performance (RT: $t(32)=2.35, p<0.05, d=0.55$; RT + EI: $t(32)=7.79, p<0.001$, $d=1.75$, respectively); and children in the RT + EI group outperformed those in the RT group $(t(32)=5.59, p<0.001, d$ $=1.01$; see Figure 1). There were no significant between-group differences for general scientific problem-solving skills (Part I: sorting and categorizing). Children's initial performance was the only significant predictor of their later performance. For specific scientific problem-solving skills (Part II: making experiments), children in RT + EI outperformed children in the control group on problem-solving skills, controlling for their initial performance $(t(32)=3.45, p<0.001, d=1.31)$. We hypothesized that explicit instruction would promote children's learning of content-specific problem-solving skills and expected children in the RT + EI group to outperform children in the RT group. There was a moderate but not significant difference between groups in the expected direction $(t(32)=1.41, p<0.10, d=0.37$; see Figure 2). Table 3 presents the posttest means for each group with significant group difference statistics, and Table 5 presents the statistics from the multi-level modeling analyses. For the first (concepts and vocabulary) and the last (making experiments) outcomes, the similarity among children within small groups in all three groups greatly decreased after controlling for the effect of teaching approaches and children's initial level of performance at pretest.

\section{Discussion}

This study examined the efficacy of two instructional approaches to teaching designed to facilitate children's learning of science concepts and vocabulary and scientific problem-solving skills in comparison to a control group: responsive teaching (RT) and the combination of responsive teaching and Explicit Instruction (RT + EI). Two carefully planned interventions implemented with preschool children provided evidence that (1) young children learned science concepts and vocabulary better when either responsive teaching or the combination of responsive teaching and 
Table 5

Statistics from multi-level modeling

Dependent Variable: Concepts-Vocabulary Time 2

Intercept

RT

RT + EI

Time 1

RT $\times$ Time 1 Estimate

23.49

2.92

9.66

0.80

$-0.07$

$\mathrm{RT}+\mathrm{EI} \times$ Time 1

$-0.16$

Dariable: Sorting and Categorizing Time 2

Effect Estimate

$\begin{array}{lr}\text { Intercept } & 7.56 \\ & 0.61\end{array}$

RT $\quad 0.61$

RT + EI

Time 1

RT $\times$ Time 1

0.80

0.61

$-0.08$

$\mathrm{RT}+\mathrm{EI} \times$ Time 1

$-0.07$

Dependent Variable: Making Experiments Time 2

Effect Estimate

Intercept 13.74

RT 1.73

RT + EI

Time 1

RT $\times$ Time 1

$\mathrm{RT}+\mathrm{EI} \times$ Time 1

Note. ${ }^{*} p<0.05$.

explicit instruction was used; (2) they learned science concepts and vocabulary better when responsive teaching and explicit instruction were used in combination than when responsive teaching alone was used; and (3) they learned scientific problem-solving skills better when explicit instruction was provided in combination with responsive teaching.

In this study, we hypothesized that children's learning about science concepts and vocabulary related to objects' floating and sinking as well as their scientific problem-solving skills would be associated with teaching approaches. Results revealed significant effects of instructional approaches on children's learning of science concepts. Children in both intervention groups significantly outperformed those in the control group on measures of science concepts and science vocabulary, and there was a significant difference in performance between children in the two intervention groups. These findings suggest that the combination of implicit and explicit teaching strategies may be more effective in teaching new concepts and vocabulary than implicit teaching strategies alone. Figure 1 shows the pattern that children have learned more concepts and vocabulary related to objects' floating and sinking when explicit teaching strategies were incorporated with implicit teaching strategies. This result is similar to that of Butts et al. (1993) and Tenenbaum et al. (2004) and the results of a series of quasi-experimental studies conducted by French and her colleagues (e.g. French, 2004). In each of these studies, researchers found that explicit instructional conversations and class lessons combined with implicit teaching involving children's exploration were beneficial for promoting children's concepts and vocabulary learning.

In addition, there was a significant difference in children's performance on content-specific scientific problem-solving skills (i.e. making floating and sinking experiments) that were taughtas part of theEIintervention. Childrenin theRT+EIgroup received significantly higher scores than did children in the control group on these tasks. The performance of children in the RT group was not significantly different from the performance of children in either the RT + EI group or the control group.

The idea of making experiments was introduced during the RT sessions in implicit ways: the implementer modeled what children could do using presented materials to make objects float or sink. In contrast, the teacher in the RT + EI intervention provided explanations and modeled strategies related to making experiments (e.g. predict, test, evaluate). The results of this study provide preliminary evidence that responsive teaching alone was less effective in promoting children's understanding of content-specific scientific problem-solving than was responsive teaching along with specific instruction and explicit guidance. When children were specifically guided through the hypothesis-making and hypothesis-testing process by teachers and explicitly encouraged to think about ways to solve problems, they used these skills to make predictions and actually solve similar problems. This result is very similar to that of a previous study by Butts et al. (1993).

Recently, a team of researchers created a preschool science curriculum, Science Start! ${ }^{\mathrm{TM}}$ that explicitly teaches children a scientific problem-solving process (i.e. Reflect-Ask $\rightarrow$ PlanPredict $\rightarrow$ Act-Observe $\rightarrow$ Report-Reflect) (French, 2004; National Research Council, 2001) along with teaching science vocabulary and concepts. Their assumption is that, if teachers model and teach this cycle of scientific thinking in science activities, children will use this approach in their everyday thinking and problem-solving experiences. Although French and her colleagues have not studied those scientific thinking skills and science-related knowledge and concepts as target outcomes, the results of the present study suggest that building preschool science curriculum around problemsolving and hypothesis-testing process may contribute to children's science learning.

We hypothesized that children in the RT + EI group would perform at a higher level than those in the RT group, and those in the RT group would perform at a higher level than those in the control group on all tasks. Although the results did not reveal a significant difference in all three outcomes (i.e. content-general and content-specific scientific problem-solving skills) between the RT and the RT + EI group, the pattern was clearly in that direction. With longer 
interventions (e.g. more intervention sessions, more tasks and various materials that can be used in objects' floating and sinking tasks, and so on) allowing children to engage in more in-depth investigation, the difference in outcomes might become more apparent.

In contrast to results related to content-specific scientific problem-solving skills (i.e. making floating and sinking experiments), children's level of content-general scientific problem-solving skills (i.e. sorting and categorizing) was not significantly different between groups. Contentgeneral problem-solving skills were not taught explicitly in either intervention but were rather implicitly embedded in the intervention sessions. That may be why there was no significant difference in children's performance between intervention and control groups. If explicit instruction had been provided in terms of content-general scientific problemsolving skills (i.e. sorting and categorizing), children might have shown significant gains as they did in terms of making floating/sinking experiments.

We created fidelity measures to examine whether or not the interventions were implemented as planned. Because interventions were implemented with high fidelity with little variation across groups, and there was evidence that the interventions were not in the control groups, fidelity data were not included in the analysis. The high fidelity scores are also a strength because they mean that the two interventions were different from each other and from the experiences of chidren in the control group.

\section{Limitations and future directions}

This study provides a few points to consider when planning future studies. First, the books read to children in the control group were all related to biology because of the lack of science books on physical phenomena for preschoolers. There are many books about nature, but books that deal with a topic related to physical science (e.g. weather, temperature, magnets) tend to be story books without explicit science information. This limited the ability to test what children learn from book reading in comparison with what children learn from more hands-on approaches as RT and RT + EI. As more children's books on physical science become available, it will be important to include them in control group activities in order to make all three groups equivalent in terms of the content being discussed in small groups.

Second, since the interventions were very short and focused, there was no evidence that they would have a longterm effect on children's overall science learning. There was no significant difference between intervention and control group children in content-general scientific problem-solving skills (i.e. sorting and categorizing) at the end of intervention. If the planned interventions had been implemented for a longer period of time, children may have been able to better learn those skills. It will be very interesting to investigate the long-term effects of these two instructional approaches for children's learning of science concepts and vocabulary and scientific problem-solving skills.

Third, the researcher in the current study implemented the interventions, so we do not know whether or not early childhood teachers would be able to effectively implement these strategies in real classrooms. It will be crucial that we try out these approaches and teaching strategies with a small group of real early childhood teachers to find out about the context where these strategies would work best, such as the length of the intervention sessions, the size of the small groups, the way that the concepts were introduced, and so on, and this will have to be done before a large efficacy study is conducted. Fourth, children's engagement in the small-group science activities may be related to children's previous experience as well as their interests in and preferences for classroom activities. In the current study, we asked parents to answer five questions about academic interaction at home, one of which was about science (i.e. engaging in science activities, such as growing seeds, experimenting with objects' floating and sinking, working with magnets, etc.). Although most children who participated in the present study were from families in which a majority of parents were well educated (represented by mother's education), their home did not provide much experience regarding science: most parents rated the item either 0 (not at all) or 1 (rarely). Investigating more in depth about what parents do at home in terms of science activities (i.e. both formally and informally) may provide additional information about children's science learning.

\section{Implications for practice}

Some developmental psychologists have suggested that young children have a limited ability to learn science concepts and scientific problem-solving skills (e.g. Brown, Campione, Metz, \& Ash, 1997). However, this study provides evidence that preschool-aged children can learn science concepts and vocabulary and age-appropriate scientific problem-solving skills when appropriate guidance and instruction are provided. Both responsive teaching and explicit instruction are useful approaches to teaching young children science concepts and vocabulary and scientific problem-solving skills at a basic level; however, incorporating explicit strategies into teaching was found to be more effective in promoting children's understanding of science concepts related to objects' floating and sinking (e.g. weight, size, float, and sink and how these concepts are related) than using implicit strategies only. Children were not expected to gain a mature understanding of concepts related to objects' floating and sinking or of the process of scientific problem solving skills after the four brief intervention sessions. Rather, they learned to define terms in a simplified way: weight (e.g. how heavy things are; heavy and light), size (e.g. how big things are; large and small), float (e.g. things stay on top of the water), and sink (e.g. things go under the water). In addition, they learned to measure and compare the weight and size of objects. The scientific problem-solving skills that children learned include making hypotheses (e.g. the object will sink if I put more things on it because it gets heavier with more things) and testing and modifying them. According to Developmentally Appropriate Practices (Copple \& Bredekamp, 2009), early childhood teachers should not only provide opportunities and materials with which children can explore their world, but they also should provide explicit instruction to help children better understand phenomena in their everyday lives (cf. Mantzicopoulos, et al., 2009).

Our RT intervention consisted of many different responsive teaching strategies, such as modeling, imitating, playing in parallel with children, describing what children are doing and saying, providing materials and ideas that challenge children's thinking, and so on. It was not that the teacher became an observer who let children explore and construct 
their own knowledge by manipulating materials, but rather, the teacher intentionally modeled what children could do with the materials and described what they were doing in order to encourage their exploration. The results of this study suggest, however, that it will be more beneficial to include explicit instructional components in teaching young children science concepts and vocabulary and content specific scientific problem-solving skills. It is also important to note that being a responsive teacher is more than just providing materials and being an observer. When the teacher used various responsive teaching strategies, children learned science concepts and vocabulary; and when more explicit instruction was added, they learned both concepts and vocabulary and scientific problem-solving skills.

Going through the process of scientific problem solving with children can be another effective method in teaching young children scientific investigation. Asking questions, making predictions, constructing hypotheses, and testing hypotheses can be an effective educational activity if explicitly guided by a teacher.

Appendix A. Sample Items from the Coding System of Children's Responses to Assessment Questions Categories

Assessment Items

Scores

SCIENCE CONCEPTS/VOCABULARY (0-42)

Average Inter-coder Percent Agreement $=89 \%$

Large, Big, Small, Heavy, Light (5 items)

1. Point to the picture of Large.

Large car/small car

5. Hold these boxes and tell me which one is Light.

Light box/heavy box

Size, Weight (2 items)

6. What is size? Do you know what size means?

I don't know/No (0)

Big (1)

Small (1)

It means that you measure people (1)

Something small and something big/little, big (2)

Float, Sink (2 items)

8 . What does it mean when we say something floats?

Do you know what float means?

I don't know/No (0)

If you put something in water then it floats away (0)

Bathtub (0), water (0)

Something floats in the water (0)

Move like a boat going down the stream/a boat (1)

Swimming. When you swim you float/you swim (1)

A boat floats (1)

It means...in water or in the air (1)

Floating stuff that has air in it (1)

Flying (1)/Flying, floating (gesture) (1)

It means it's light (2)

Something is on the water like a boat and a chip (2)

It means that you stay up at the top of the water (2)

Larger, Bigger, Smaller, Heavier, Lighter (5 items) 10. Which one is Larger?

Large circle/small circle

$0=$ incorrect

13. Which side is Heavier?

Picture of a balance scale with objects

15-1. Look at these pictures. Which one is like the one on the top?

Size (1 large circle on top; 3 small and 1 large circles)

15-2. Why?

17-1. Hold this box (heavy one). You can hold each of these boxes and tell me which one is like the one that you have.

Weight (1 heavy box; 3 lighter and 1 heavy box)

17-2. Why?

Floating (2 items)

19-1. I have two bottles. If I put them in water, only one of them will float. Which one do you think will float?

Same size/different weight (a bottle with water vs. an empty bottle)

19-2. Why?

It doesn't have any water in it (1)

It's empty (1)

Sinking (2 items)

21-1. I have two pipes. If I put them in water, only one of them will

sink. Which one do you think will sink?

Same size/different weight (a plastic pipe vs. a metal pipe)

21-2. Why?

VOCABULARY/CONCEPTS

TOTAL SCORE

CONTENT-GENERAL SCIENTIFIC PROBLEM-SOLVING SKILLS (0-10)

Average Inter-coder Percent Agreement $=98 \%$

1. Look at these boxes. Show me how you can put them in order by size.

Sorting and Categorizing (4 items) 4 boxes in different sizes

$0=$ incorrect

$1=$ correct

$0=$ incorrect

$1=$ correct

$0=$ incorrect

1 = acceptable

$2=$ correct

$0=$ incorrect

$1=$ acceptable

$2=$ correct

$0=$ incorrect

$1=$ correct

$0=$ incorrect

$1=$ correct

$0=$ incorrect

1 = acceptable

2 = correct

$0=$ incorrect

1 = correct

$0=$ incorrect

1 = acceptable

2 = correct

$0=$ incorrect

$1=$ correct

$0=$ incorrect

$1=$ acceptable

$2=$ correct

$0=$ incorrect

$1=$ correct

$0=$ incorrect

1 = acceptable

2 = correct

$0=$ failed

$1=2$ corrects

$2=3$ corrects

$3=4$ corrects 
4. Look at these water bottles. Some are heavy, and some are light.

Show me how you can put them in groups. How can you put them

$0=$ incorrect in groups? 2 = correct

3 bottles with little water and 3 bottles filled with water

SCIENTIFIC PROBLEM-SOLVING SKILLS PART I

\section{TOTAL SCORES}

CONTENT-SPECIFIC SCIENTIFIC PROBLEM-SOLVING SKILLS (0-22)

Average Inter-coder Percent Agreement $=92 \%$

Making experiments ( 2 items)
15. I have toys in the water here. I am going to put this foil container in the water. What happened? It floats in water. See? It floats.

15-1. Tell me what you can do to make it sink. How can you make it sink?

0 : I don't know or no response

1: Go under water

1: You turn it and it will sink

1: If it's small and if it's not heavy then it will float

1: If it's a smaller pan

1: Add/put more water in this box (water box, not the container)

1: Make it (container) smaller

1: Touch and move it around

2: Push it down; put your hand on it; put it under water

2: Turn it over and push it down

3: Hole in it

3: Put big balls in it

3: Put something very big in there

3: Put too much water in it (container)

3: Put things (balls, blocks, toys, stuff, etc.) in it

4: Put heavy things in it/on top of it

$15-2$. Now, pull your sleeves up and make it sink. You can touch the toys inside now.

1. Success/Failure and \# of Trials (0-3)

- I don't know or No trial (0)

- One trial but failed and gave up (1)

- Two or more trials but failed and gave up (2)

- Succeeded after one or more trials (3)2. Child's action

- Use the codes for 15-1

SCIENTIFIC PROBLEM-SOLVING SKILLS PART II TOTAL SCORE
References

Berk, L.E., and A. Winsler (1995). Scaffolding Children's Learning. Washington, D.C.: National Association for the Education of Young Children.

Bredekamp, S., and T. Rosegrant (1995). Reaching Potentials: Transforming Early Childhood Curriculum and Assessment. Washington, D.C.: National Association for the Education of Young Children.

Brown, A.L., J.C. Campione, K.E. Metz and D.B. Ash (1997). The development of science learning abilities in children. In: K. Harnqvist and A. Burgen (Eds.), Growing up with Science: Developing Early Understanding of Science (pp. 7-40). Bristol, Pa.: Jessica Kingsley, Academia Europaea.

Butts, D., H. Hoffman and M. Anderson (1993). Is hands-on experience enough? A study of young children's views of sinking and floating objects. Journal of Elementary Science Education 5: 50-64.

Chaille, C., and L. Britain (1991). The Young Child as Scientist: A Constructivist Approach to Early Childhood Science Education. New York: HarperCollins.

Copple, C., and S. Bredekamp (2009). Developmentally Appropriate Practice in Early Childhood Programs Serving Children from Birth through Age 8 ( $3^{\text {rd }}$ ed.). Washington, D.C.: National Association for the Education of Young Children.

Dodge, D.T., L.J. Colker and C. Heroman (2002). The Creative Curriculum for Preschool ( $4^{\text {th }}$ ed.). Washington, D.C.: Teaching Strategies.

Forman, G.E., and D.S. Kuschner (1983). The Child's Construction of Knowledge: Piaget for Teaching Children. Washington, D.C.: National Association for the Education of Young Children.

French, L. (2004). Science as the center of a coherent, integrated early childhood curriculum. Early Childhood Research Quarterly 19: 138-149. DOI: 10.1016/j. ecresq.2004.01.004.

French, L., K. Conezio and M. Boynton (2000). Using Science as the Hub of an Integrated Early Childhood Curriculum: The Science Start! ${ }^{\mathrm{TM}}$ Curriculum. Arlington, Va.: National Science Foundation. (ERIC Document Reproduction Service No. ED470901).

Greenfield, D.B., J. Jirout, X. Dominguez, A. Greenberg, M. Maier and J. Fuccillo
(2009). Science in the preschool classroom: A programmatic research agenda to improve science readiness. Early Education and Development 20: 238-264. DOI: 10.1080/10409280802595441.

Mantzicopoulos, P., A. Samarapungavan and H. Patrick (2009). “We learn how to predict and be a scientist": Early science experiences and kindergarten children's social meaning about science. Cognition and Instruction 27: 312369. DOI: $10.1080 / 07370000903221726$.

Mather, N., and R.W. Woodcock (2001). Woodcock-Johnson III Tests of Achievement. Rolling Meadows, Ill.: Riverside Publishing.

National Research Council. (1996). National Science Education Standards. Washington, D.C.: National Academy Press.

National Research Council. (2001). In: B.T. Bowman, M.S. Donovan and M.S. Burns (Eds.), Eager to Learn: Educating our Preschoolers. Committee on Early Childhood Pedagogy. Commission on Behavioral and Social Sciences and Education. Washington, D.C.: National Academy Press.

Rogoff, B. (1990). Apprenticeship in Thinking: Cognitive Development in Social Context. New York: Oxford University Press.

Roopnarine, J.L., A. Krishnakumar, A. Metindogan and M. Evans (2006). Links between parenting styles, parent-child academic interaction, parentschool interaction, and early academic skills and social behaviors in young children of English-speaking Caribbean immigrants. Early Childhood Research Quarterly 21: 238-252. DOI: 10.1016/j.ecresq.2006.04.007.

Scott-Little, C., S.L. Kagan and V.S. Frelow (2006). Conceptualization of readiness and the content of early learning standards: the intersection of policy and research? Early Childhood Research Quarterly 21: 153-173. DOI: 10.1016/j.ecresq.2006.04.003.

Tenenbaum, H.R., G. Rappolt-Schlichtmann and V.V. Zanger (2004). Children's learning about water in a museum and in the classroom. Early Childhood Research Quarterly 19: 40-58. DOI: 10.1016/j.ecresq.2004.01.008.

Vygotsky, L.S. (1978). Mind in Society: The Development of Higher Psychological Processes. Cambridge, Mass.: Harvard University Press. 